\title{
AVALIAÇÃO DA TRANSFERÊNCIA DE FISSURAS EM SISTEMAS DE IMPERMEABILIZAÇÃO ADERIDOS
}

\author{
EVALUATION OF CRACK BRIDGING IN ADHERED WATERPROOFING SYSTEMS
}

\author{
Dulie Anne Braun dos Santos 1 \\ (D)Felipe Pereira Santos ${ }^{2}$ \\ (Denata Monte ${ }^{3}$ \\ 1 Universidade de São Paulo, São Paulo, SP, \\ Brasil, julie.braun@usp.br \\ 2 Universidade de São Paulo, São Paulo, \\ SP, Brasil, felipe.pereira.santos@usp.br \\ 3 Universidade de São Paulo, São Paulo, \\ SP, Brasil, renata.monte@usp.br
}

Contribuição dos autores:

JABS: conceituação, curadoria de dados, investigação, metodologia, administração do projeto, recursos, programas, supervisão, validação, visualização, escrita - rascunho original, escrita - revisão e edição. FPS: conceituação, curadoria de dados, investigação, metodologia, validação. RM: conceituação, curadoria de dados, investigação, metodologia, administração do projeto, recursos, programas, supervisão, validação, visualização, escrita - rascunho original, escrita - revisão e edição.

Fomento: Não houve fomento Conflito de interesse: declara não haver

Editor Responsável:

Guilherme Aris Parsekian

\begin{abstract}
Resumo
Sistemas de impermeabilização aderidos em estruturas de concreto formam barreiras protetoras contra a entrada de fluídos e agentes agressivos. No entanto, se fissuras surgirem no substrato e passarem para a camada impermeável aderida, a estanqueidade do sistema pode ser comprometida. Esse trabalho tem como objetivo a avaliação experimental do comportamento de duas membranas impermeabilizantes, de base acrílica, quando aderidas em substrato de concreto sujeito a fissuração. É proposto um método de ensaio mecânico de tração indireta associado a análise por correlação de imagem (DIC) para avaliação da transferência de fissuras de substratos de concreto para membranas impermeabilizantes aderidas. Os resultados mostraram que esta metodologia permite diferenciar o comportamento das membranas com relação a transferência de fissuras. Além disto, foi possível mensurar quantitativamente, com a técnica DIC, a magnitude da fissura no concreto que resultou em fissuração nas membranas. A membrana de acrilatos puros resultou menor capacidade de absorver os esforços provenientes do substrato do que a membrana de copolímeros acrílicos sem cimento. Esse comportamento pode ser relacionado com a diferença no alongamento dos materiais. A aderência das membranas ao substrato foi elevada e muito superior aos requisitos normativos, e pode ter resultado na dificuldade das membranas de absorver os esforços do substrato, fissurando com maior facilidade.
\end{abstract}

Palavras-chave: Transferência de fissuras. Sistemas de impermeabilização. Membranas impermeabilizantes aderidas. Análise por correlação de imagem digital 2D.

\begin{abstract}
Waterproofing systems adhered to concrete structures produce a protective barrier against fluids and aggressive agents' penetrations. However, if cracks appear in the substrate and are transmitted to the adhered waterproof layer, the system's water tightness can be compromised. This work aims to perform an experimental evaluation of two waterproofing membranes' behavior, based on acrylic, when adhered to concrete substrates subject to cracking. A mechanical test method based on indirect tensile stress associated with Digital Image Correlation analysis (DIC) is proposed to assess the transfer of cracks from concrete substrates to bonded waterproofing membranes. The results showed that this methodology allows distinguishing the membranes' behavior concerning the transfer of cracks. It was also possible to measure quantitatively, with the DIC technique, the degree of crack in the concrete that resulted in cracking in the membranes. The pure acrylates membrane resulted in less stress dissipation from the substrate than the acrylic copolymer without cement membrane. This behavior can be related to the difference in the elongation of the materials. The adhesion of the membranes to the substrate was high and considerably higher than the normative requirements, and can be associated with the membrane's difficulty in dissipating the substrate stress, cracking more easily.
\end{abstract}

Keywords: Crack bridging ability. Waterproofing systems. Adhered waterproofing systems. 2D digital image correlation. DIC.

How to cite this article:

SANTOS, J. A. B. dos; SANTOS, F. P.; MONTE, R. Avaliação da transferência de fissuras em sistemas de impermeabilização aderidos. PARC Pesquisa em Arquitetura e Construção, Campinas, SP, v. 12, p. e021003, 2021. DOI:

http://dx.doi.org/10.20396/parc.v12i00.8661114 


\section{Introdução}

O sistema de impermeabilização tem como funções: (i) a preservação da integridade dos elementos estruturais e funcionalidade da edificação, (ii) conforto e salubridade dos ambientes visando o usuário (KUBAL, 2008, p. 33). No entanto, para que este sistema seja efetivo deve ser ponderada uma integração de fatores tais como: seleção correta dos materiais compatíveis com o substrato e as solicitações, da localização da edificação e condições ambientais, e meios sob os quais os sistemas serão submetidos (SRIRAVINDRARAJAH; TRAN, 2018).

No processo de seleção do material impermeabilizante é importante considerar o comportamento deste quando aderido ao substrato de concreto (ZHAO; LI; ZHANG, 2015). Isto porque os elementos de concreto são rígidos e em resposta a reações físicas, quando no estado endurecido, estão sujeitos ao processo de fissuração (ISSA; DEBS, 2007). Segundo Neville (2016), há tendência de início de infiltração em fissuras com aberturas entre $0,12 \mathrm{~mm}$ a $0,20 \mathrm{~mm}$. Com a percolação de fluídos, processos de degradação podem ocorrer em estruturas de concreto armado (GRIBNIAK et al., 2020; VAN LOOCK; FLECK, 2018). Desta forma, é essencial que a camada impermeabilizante suporte estas fissuras para garantir a estanqueidade do sistema (DIAMANTI et al., 2013; KONG et al., 2018).

A capacidade da camada impermeabilizante acomodar integralmente as fissuras do substrato é denominada Crack bridging ability (AMERICAN SOCIETY FOR TESTING AND MATERIALS, 2016; EUROPEAN STANDARD, 2004). As pesquisas que abordam a transferência de fissuras do substrato para a membrana são geralmente realizadas por meio de ensaios mecânicos de tração direta (DELUCCHI et al., 2002; DELUCCHI; CERISOLA, 2005; HOLTER, 2016; JAEGERMANN; PUTERMAN, 1987; WALDVOGEL et al., 2020b). Porém, os ensaios de tração direta de materiais frágeis, como o concreto, não são simples, pois a ruptura ocorre de forma abrupta (RANJ BARIAN; MA; MECHTCHERINE, 2020). Isto dificulta o acompanhamento da fissuração e a medida da abertura da fissura no tempo, fazendo com que o ensaio seja muitas vezes utilizado de maneira qualitativa.

Como alternativa, para obtenção de uma propagação estável da fissura, podem ser considerados o uso de fibras na composição do corpo de prova (LIU; ZHANG; LIEW, 2020), assim como ensaios indiretos como o WST (Wedge Splitting Test) ou método da cunha. Esse ensaio tem sido utilizado com essa finalidade para avaliar energia de fratura em materiais cerâmicos (BRÜHWILER; WITTMANN, 1990; RIBEIRO et al., 2008; SEGURACASTILLO; MONTE; DE FIGUEIREDO, 2018).

O acompanhamento das fissuras nos ensaios de Crack bridging ability é complexo, especialmente devido à dificuldade de instrumentação da camada impermeabilizada. Waldvogel et. al (2020b) sugere o uso da análise por correlação de imagem digital (Digital Image Correlation- DIC). Para esses autores, o uso desta técnica de análise possibilita o monitoramento da deformação e da abertura de fissura, assim como o surgimento de tensões próximas da zona fissurada.

Neste contexto, o trabalho propõe uma metodologia experimental com aplicação de um ensaio mecânico de tração indireta associado a análise por correlação de imagem (DIC) para avaliação da transferência de fissuras de substratos de concreto para membranas impermeabilizantes aderidas. 


\section{Fundamentação}

\section{Transferência de fissuras-Crack bridging}

A transferência de fissuras do substrato para o sistema de impermeabilização aderido (Crack bridging) tem sido pesquisada desde 1987 por Jaegermann e Puterman. Esses autores perceberam a ocorrência deste fenômeno em lajes de cobertura em edificações e identificaram este como sendo a causa primária de falhas em membranas e mantas impermeabilizantes, principalmente quando expostas a radiação solar.

Os estudos baseiam-se na premissa que havendo fissuras no substrato de concreto poderá haver transferência de esforços para o sistema de impermeabilização aderido, tendendo a abrir fissuras neste também (DELUCCHI et al., 2002; HOLTER, 2016; WALDVOGEL et al., 2020a; ZHAO; LI; ZHANG, 2015). Como consequência, a camada impermeabilizante fissurada poderá permitir a passagem dos fluidos (MENGEL; KRAUSS; LOWKE, 2020), iniciando processos de degradação (GLASSER; MARCHAND; SAMSON, 2008).

Waldvogel et al (2020a) explica a evolução no tempo da transferência de fissura do substrato para a camada impermeabilizante aderida, conforme apresenta a Figura 1.

Figura 1- Representação da evolução da transferência de fissura (Crack bridging) do substrato para a membrana aderida

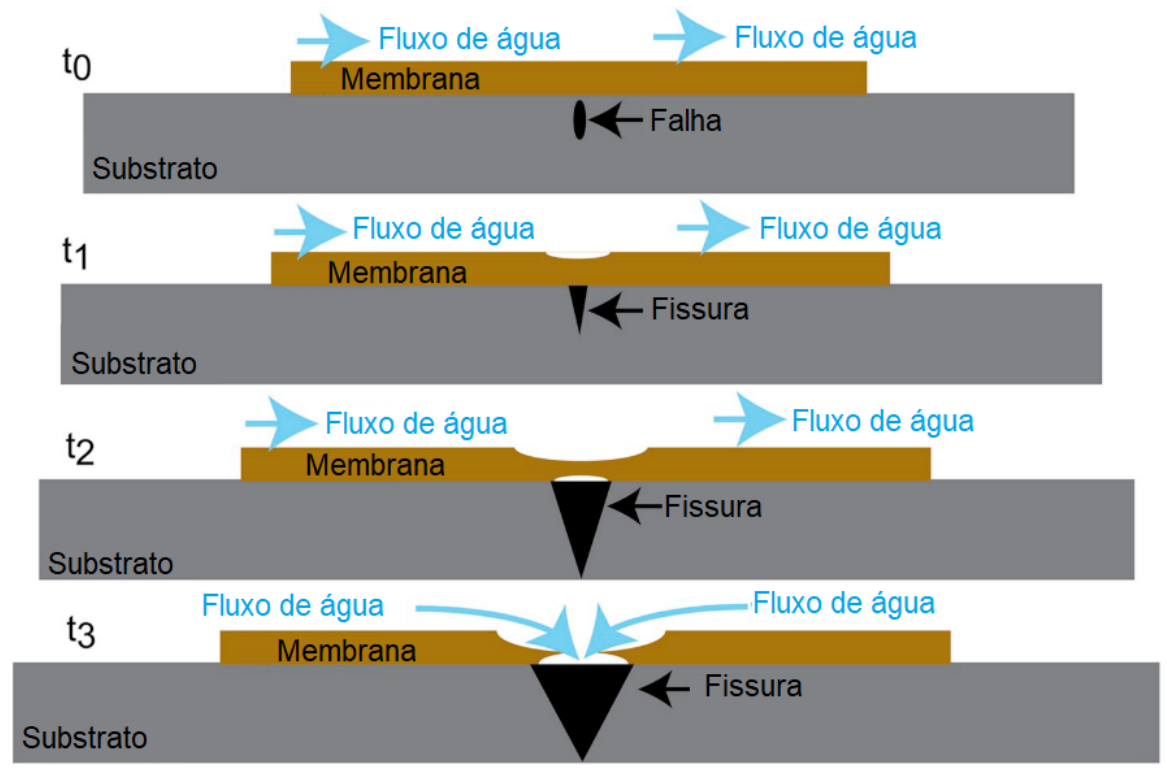

Fonte: Adaptado de Waldvogel et al. (2020a).

Inicialmente (instante to), observa-se que a membrana, em estado relaxado, proporciona estanqueidade ao fluxo de água, e ocorre uma falha no substrato. Com o aumento das tensões, no estágio t1, é iniciada a fissuração no substrato e a membrana começa a se deformar. No estágio t2, apesar das solicitações do substrato, a membrana segue deformando sem fissurar. Em um último momento ( $\mathrm{t} 3$ ), a abertura de fissura no substrato é máxima e o alongamento da membrana atinge o limite de ruptura. Neste último estágio a transferência de fissura é finalizada e a membrana se rompe.

A resistência a propagação dessa fissura será função da composição, das propriedades mecânicas e da espessura da membrana (DELUCCHI; BARBUCCI; CERISOLA, 2004; DELUCCHI; CERISOLA, 2005; WALDVOGEL et al., 2020a), assim como das condições externas, como a temperatura (DELUCCHI; CERISOLA, 2012; EUROPEAN 
ORGANISATION FOR TECHNICAL APPROVALS., 2009; WALDVOGEL et al., 2020b) e a magnitude das movimentações do substrato (HOLTER, 2016).

Os materiais impermeabilizantes, em sua maioria compostos por polímeros, são caracterizados por apresentar comportamento elástico, com grandes deformações antes da ruptura (CALLISTER, 2018, p. 251). Apesar do alongamento por si só não qualificar um material impermeabilizante como resistente à transferência de fissuras (ZHAO; LI; ZHANG, 2015), esta propriedade é considerada um fator relevante.

Sistemas compostos por membranas poliméricas ou cimentícias com adição de polímeros apresentam melhor capacidade de absorção das fissuras, devido a flexibilidade e menor módulo de elasticidade (DIAMANTI et al., 2013). No entanto, aqueles com resistência à tração mais elevada, por apresentar maior rigidez, consequentemente se tornam menos aptos a suportar aberturas de fissura (DELUCCHI et al., 2002).

Waldvogel et al. (2020b) identificaram que a perda de aderência de parte da membrana do substrato proporcionou aumento da capacidade de absorção dos esforços. Assim, à medida que ocorre diminuição da aderência na zona fissurada maior é a tendência do material impermeabilizante alongar e manter a proteção do substrato fissurado (DELUCCHI et al., 2002; WALDVOGEL et al., 2020b).

Metodologias de ensaio: normas e guias

A norma Europeia EN 1062-7 (2004) conceitua Crack bridging como a "capacidade do revestimento ou do sistema em absorver a deformação resultante da transferência da fissura". A norma americana ASTM C1305/C1305M (2016) utiliza este termo para indicar "a capacidade de uma membrana impermeabilizante manter a sua integridade quando uma fissura preexistente no substrato é transmitida".

As principais referências normativas e guias que apresentam ensaios para simular a transferência de fissuras do substrato para a camada aderida estão apresentadas no Quadro 1.

\begin{tabular}{|c|c|c|c|}
\hline Referências & Aplicação & Materiais/sistemas & Condições de ensaio \\
\hline EN 1062-7 (2004) & Alvenarias e concreto & Tintas e vernizes & De $23^{\circ} \mathrm{C}$ a $-40^{\circ} \mathrm{C}$ \\
\hline EOTA TR 013 (2004) & Coberturas de concreto & Membranas impermeabilizantes & $-30^{\circ} \mathrm{C} \pm 2^{\circ} \mathrm{C}$ \\
\hline EN 14224 (2010) & $\begin{array}{l}\text { Tabuleiros de pontes e áreas de } \\
\text { tráfego de veículos em concreto }\end{array}$ & Membranas e mantas asfálticas & De $0^{\circ} \mathrm{Ca}-30^{\circ} \mathrm{C}$ \\
\hline EOTA ETAG 033 (2010) & $\begin{array}{l}\text { Tabuleiros de pontes e áreas de } \\
\text { tráfego de veículos em concreto } \\
\text { (referência EN14224) }\end{array}$ & $\begin{array}{l}\text { Membranas base: acrílica, epóxi, } \\
\text { poliéster, poliureia, poliuretano e } \\
\text { polímeros dispersos em água }\end{array}$ & De $0{ }^{\circ} \mathrm{Ca}-30^{\circ} \mathrm{C}$ \\
\hline ASTM C1305 (2016) & Não declara aplicação específica & Membranas impermeabilizantes & $-26^{\circ} \mathrm{C} \pm 1^{\circ} \mathrm{C}$ \\
\hline EN 14891 (2017) & $\begin{array}{l}\text { Assentamento de revestimentos em } \\
\text { paredes externas, pisos e piscinas }\end{array}$ & Argamassa modificada com polímeros & De $23^{\circ} \mathrm{Ca}-20^{\circ} \mathrm{C}$ \\
\hline
\end{tabular}

Como observado, as referências normativas e guias indicam as possíveis condições de exposição ao meio, cujas variações de temperatura partem do ambiente $\left(23^{\circ} \mathrm{C}\right)$ até abaixo de zero $\left(-40^{\circ} \mathrm{C}\right)$. Estas situações são consideradas críticas para os materiais poliméricos, pois podem sofrer perda de deformação e flexibilidade quando em temperatura abaixo da $\mathrm{Tg}$ (WALDVOGEL et al., 2020a).

Apesar de haver diferentes abordagens, o princípio básico do ensaio é semelhante. Em todos os métodos se deseja avaliar o comportamento de impermeabilizantes aderidos em substratos, de concreto ou argamassa. Porém, esses procedimentos normativos 
apresentam como resultado a medida da abertura de fissura no substrato quando a abertura de fissura na membrana se torna visível.

Para Waldvogel et al. (2020b), antes da formação da fissura propriamente, pode haver o surgimento de bulbos de tensões em torno da região que tende a sofrer ruptura. Este processo é difícil de ser percebido e avaliado visualmente. Contudo, conforme sugerido pelos citados autores o monitoramento com uso da tecnologia de correlação de imagens digitais permitiria uma melhor visualização do processo de deformação e do surgimento da fissura.

Análise por correlação de imagem digital (DIC)

A correlação de imagem digital (DIC) consiste em uma técnica para medição de deslocamentos superficiais de peças sólidas quando em movimento ou estáticos (INTERNATIONAL DIGITAL IMAGE CORRELATION SOCIETY, 2018). Caracterizada como uma técnica de base ótica, mede coordenadas em duas (2D) ou três dimensões (3D) de uma superfície durante ensaios mecânicos (DEL REY CASTILLO et al., 2019).

Em paralelo com os equipamentos físicos, como extensômetros ópticos ou mecânicos, que medem em uma única direção a deformação dos materiais, a técnica DIC tem sido utilizada como um medidor independente do material ensaiado (DEL REY CASTILLO et al., 2019). Isto indica que por meio desta técnica as deformações podem ser medidas em várias direções, capturando alterações de tensões ao longo do objeto (INTERNATIONAL DIGITAL IMAGE CORRELATION SOCIETY, 2018).

Para a obtenção das imagens em 2D é necessário restringir o campo óptico da câmera a região de interesse (Region Of Interest - ROI) do objeto a ser estudado. As movimentações que ocorrem fora deste plano podem gerar erros de medição caso as imagens tenham distorções (SUTTON et al., 2008).

O fundamento da técnica DIC consiste em um algoritmo que calcula o deslocamento dos elementos de uma superfície em um conjunto de imagens consecutivas antes e após a deformação (Figura 2). Por meio de um padrão aleatório de pontos, também chamado padrão estocástico, as imagens de referência são comparadas com as deformadas (CHIEN et al., 2019).

Figura 2- Exemplo do funcionamento da técnica DIC para ensaio mecânico de tração, (esquerda) a amostra recebe o padrão de pontos, (ao centro) a imagem deformada é capturada e (a direita) é feita comparação do deslocamento dos pontos na superfície da amostra com base na imagem de referência

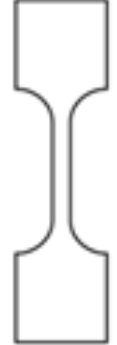

Sem os pontos

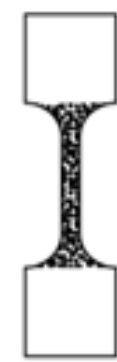

Padrão de pontos

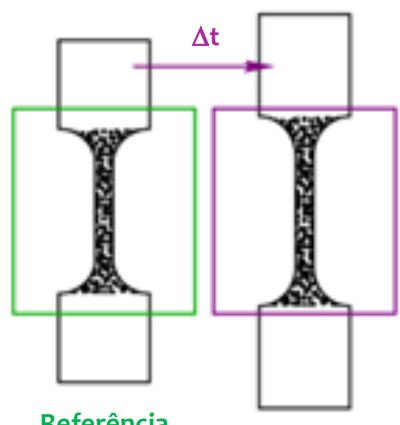

Deformado

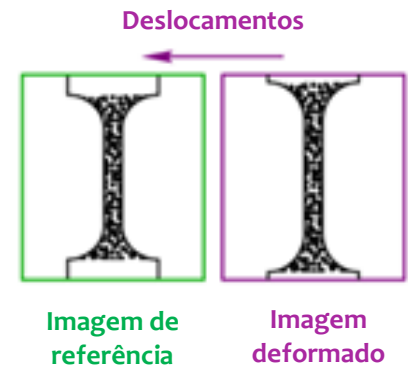

referência

Fonte: digitalimagecorrelation.org

O padrão de pontos é usualmente criado na superfície com auxílio de tinta spray. A cor branca para pano de fundo da superfície e preta para a formação do padrão é recomendado devido ao contraste inerente (LEPAGE; SHAW; DALY, 2017). O processo 
de preparação das amostras é importante, pois falhas na malha de pontos acarretam em perda da leitura do deslocamento dos pixels durante o processamento das imagens.

\section{Materiais e métodos}

O estudo experimental envolveu uma metodologia desenvolvida para avaliar a transferência de fissuras (Crack bridging) em sistemas de impermeabilização aderidos a substratos de concreto. Para o estudo foram selecionados dois materiais impermeabilizantes: a membrana de copolímeros acrílicos e a membrana acrílica sem cimento. O ensaio da transferência de fissuras (Crack bridging) apresentou uma proposta metodológica que difere em dois aspectos das normas e pesquisas anteriores. O primeiro é a utilização de um ensaio de tração indireta, para obtenção de propagação estável da fissura. O segundo consistiu no monitoramento simultâneo da abertura de fissura no substrato e na membrana, com uso da técnica de análise por Correlação de Imagem Digital em duas dimensões (DIC-2D). Com essas análises pretendeu-se diferenciar o comportamento das diferentes membranas frente a fissuração do substrato. Além disso, a resistência de aderência das membranas (pull-off test) foi determinada após o ensaio de Crack bridging, buscando relacionar a eventual perda de aderência com a capacidade de absorver tensões do substrato.

O substrato utilizado foi cúbico de aresta $150 \mathrm{~mm}$, produzido de concreto de $\mathrm{f}_{\mathrm{ck}}$ igual a $30 \mathrm{MPa}$ e com adição de $20 \mathrm{~kg} / \mathrm{m}^{3}$ de fibras de aço. A incorporação de fibras teve apenas a finalidade de controlar a abertura após a fissuração do concreto, não interferindo no comportamento da camada de impermeabilização. Para estes experimentos foram selecionados dois sistemas impermeabilizantes de base polimérica: uma membrana de acrilatos puros (MAP) e uma membrana de copolímeros acrílicos sem cimento (MASC).

Além das diferenças na composição e propriedades mecânicas (Tabela 1), estes materiais formam sistemas impermeabilizantes para distintas aplicações. A MASC é indicada, segundo a norma NBR 15885 (ASSOCIAÇÃO BRASILEIRA DE NORMAS TÉCNICAS, 2010), para impermeabilização de substratos cuja frequência de contato com a água seja constante ou eventual, como áreas frias, juntas de fachada, reservatórios e varanda. Além disto, devido à resistência a alcalinidade este material é passível de receber camadas de revestimentos.

A MAP, normalizada pela NBR 13321, é projetada para impermeabilização de áreas que tenham exposição a intempéries (ASSOCIAÇÃO BRASILEIRA DE NORMAS TÉCNICAS, 2008). Dentre os exemplos de aplicação desse tipo de membrana estão as lajes com pequenos vãos, marquises, canaletas e alvenarias externas. Por ser resistente aos raios UV e ao tráfego eventual para manutenção, esse é considerado um sistema autoprotegido. O Quadro 2 apresenta as características das membranas utilizadas no estudo.

Quadro 2- Características das membranas de acrilatos puros (MAP) e de copolímeros acrílicos sem cimento (MASC)

\begin{tabular}{|c|c|c|}
\hline Características & $\begin{array}{c}\text { Membrana de acrilatos puros (NBR } \\
\text { 13321) }\end{array}$ & $\begin{array}{c}\text { Membrana de copolímeros acrílicos } \\
\text { sem cimento (NBR 15885) }\end{array}$ \\
\hline Cor & Branca & Cinza \\
\hline Densidade (g/cm $\mathbf{3}$ ) & 1,40 & 2,45 \\
\hline Alongamento na ruptura (\%) & 160 & 0,91 \\
\hline Resistência à Tração (MPa) & 2,00 & 2 \\
\hline Secagem ao toque (h) & 4 & 1,0 \\
\hline Consumo (kg/m $\mathbf{2})$ & 1,2 & 0,5 a 1 \\
\hline Espessura total seca (mm) & 0,5 a 1 & Líquido monocomponente \\
\hline Estado para aplicação & Líquido monocomponente & \\
\hline
\end{tabular}

Fonte: Adaptado dos relatórios dos ensaios e ficha técnica fornecidos pelo fabricante. 


\section{Preparação dos corpos de prova}

O substrato cúbico de concreto recebeu no topo um entalhe de $25 \mathrm{~mm}$ de profundidade, produzido com o auxílio de uma serra circular fixada, por onde o esforço mecânico para abrir a fissura foi conduzido com uso de uma cunha metálica. As membranas foram aplicadas em uma das faces laterais, ortogonalmente ao entalhe. A aplicação e consumo $\left(\mathrm{kg} / \mathrm{m}^{2}\right)$ teve como referência as instruções indicadas pelo fabricante, constantes na Tabela 1.

O processo consistiu da aplicação em 3 demãos do material, com intervalo de 4 horas entre as camadas. A primeira, com diluição de $10 \%$, teve como objetivo uniformizar a superfície e criar uma ponte de aderência entre o substrato e as demais camadas. A demais demãos foram aplicadas sem diluição. Para o controle de massa do material aplicado foi utilizada balança eletrônica com precisão de 0,01 g. A quantidade aplicada por demão foi controlada através da pesagem do recipiente com o material e o pincel, antes e após cada aplicação. A Figura 3 ilustra o substrato com a membrana de acrilatos puros aplicada (a esquerda) e o substrato com a membrada de copolímeros acrílicos (a direita).

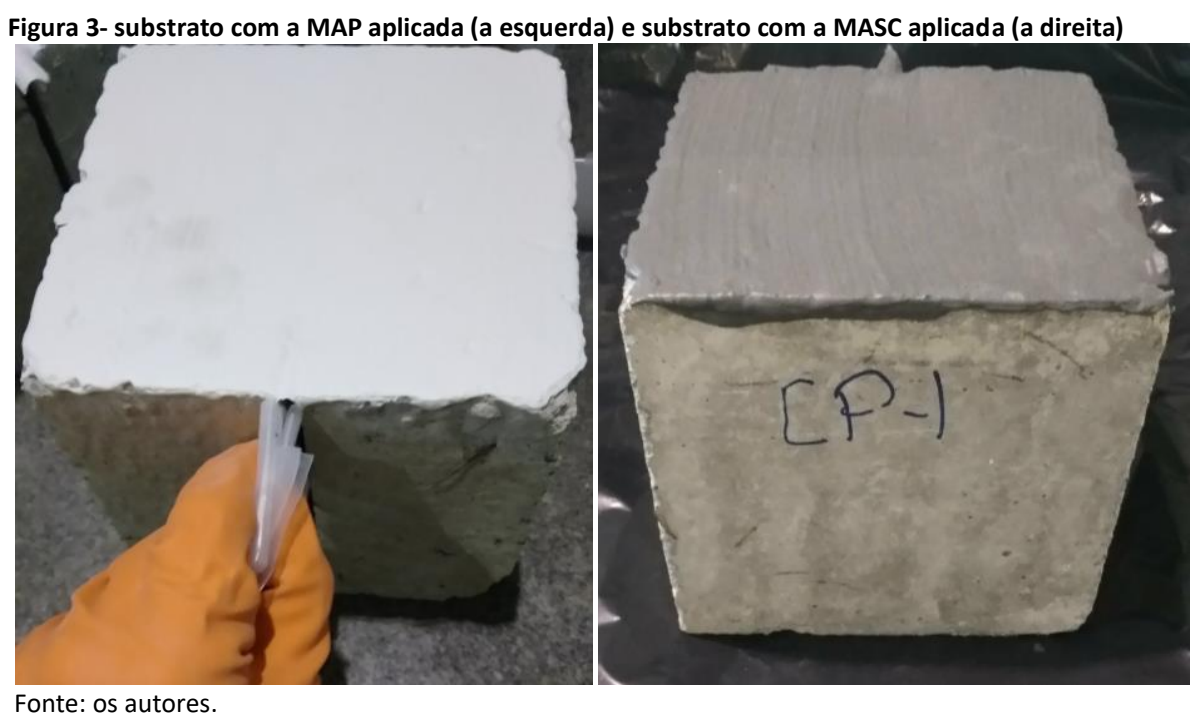

O controle da umidade e da temperatura foi feito com uso de um termo higrômetro digital com faixa de medição entre $0^{\circ}$ a $50^{\circ} \mathrm{C}$ e umidade relativa do ar entre $0 \%$ a $80 \%$, exatidão de $\pm 1^{\circ} \mathrm{C}$ e $\pm 5 \%$ UR, respectivamente.

Os corpos de prova permaneceram a temperatura ambiente $(23 \pm 2)^{\circ} \mathrm{C}$ durante 28 dias para cura das membranas. A espessura do filme seco foi mensurada com auxílio de um paquímetro, obtendo a média de 1,13 $\mathrm{mm}$ para a MAP e 1,17 mm para a MASC.

Ao término deste período, os corpos de prova foram preparados para serem submetidos aos ensaios de transferência de fissuras. A face impermeabilizada foi preparada para possibilitar que as deformações e aberturas de fissura fossem medidas através da correlação por análise de imagem (DIC). Assim, a aplicação de uma fina camada de tinta branca spray foi feita (Figura 4 a esquerda). Finalizada esta etapa foi utilizado um carimbo de dimensões $150 \mathrm{~mm}$ x $150 \mathrm{~mm}$ para marcação da malha de padrão estocásticos sobre cada membrana (Figura 4 a direita). 
SANTOS, J. A. B. dos; SANTOS, F. P.; MONTE, R.

Avaliação da transferência de fissuras em sistemas de impermeabilização aderidos

Figura 4- Preparação dos corpos de prova para análise por DIC: aplicação de tinta spray na cor branca (a esquerda) e aplicação da malha de pontos com uso de carimbo com tinta na cor preta (a direita)

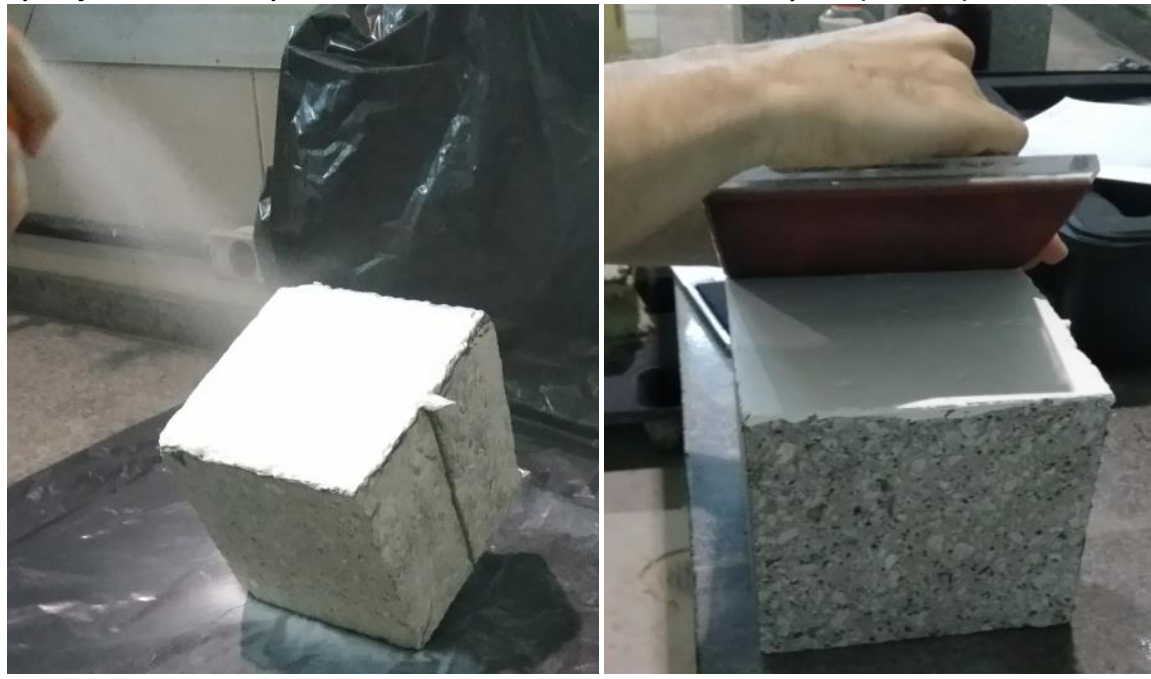

Fonte: os autores.

Conforme mostra a Figura 5, o padrão estocástico de pontos foi aplicado na cor preta, que em contraste com o fundo branco, representou entre 4 a 8 pixels da imagem.

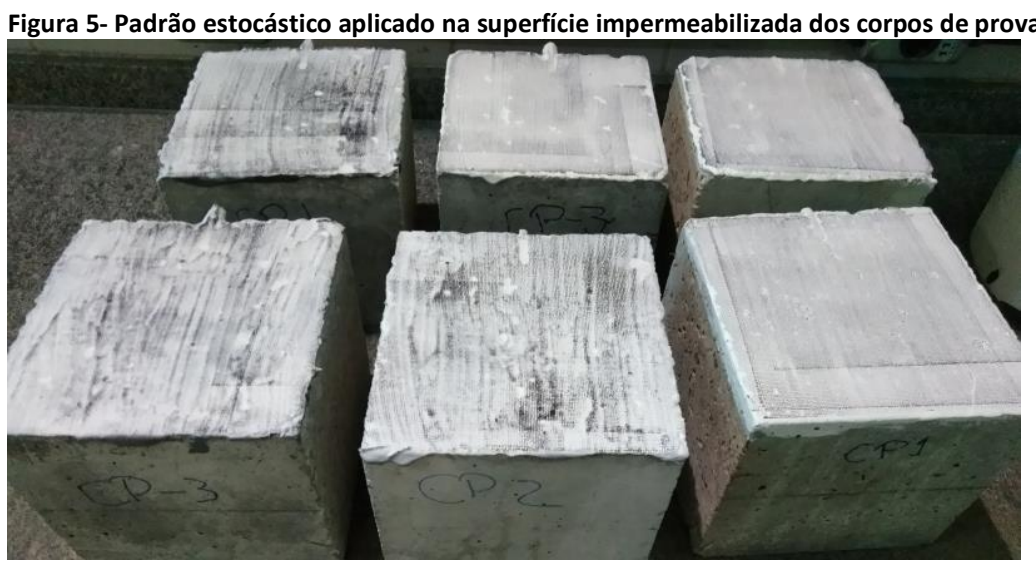

Fonte: os autores.

$\mathrm{Na}$ face oposta a impermeabilizada foram instalados insertes metálicos com o uso de massa adesiva de base epóxi (Figura 6). Estes insertes foram destinados à fixação de um transdutor LVDT (Linear Variable Differential Transformer Devices) para leitura dos deslocamentos do substrato.

Figura 6- Aderência de insertes metálicos na face oposta a impermeabilizada

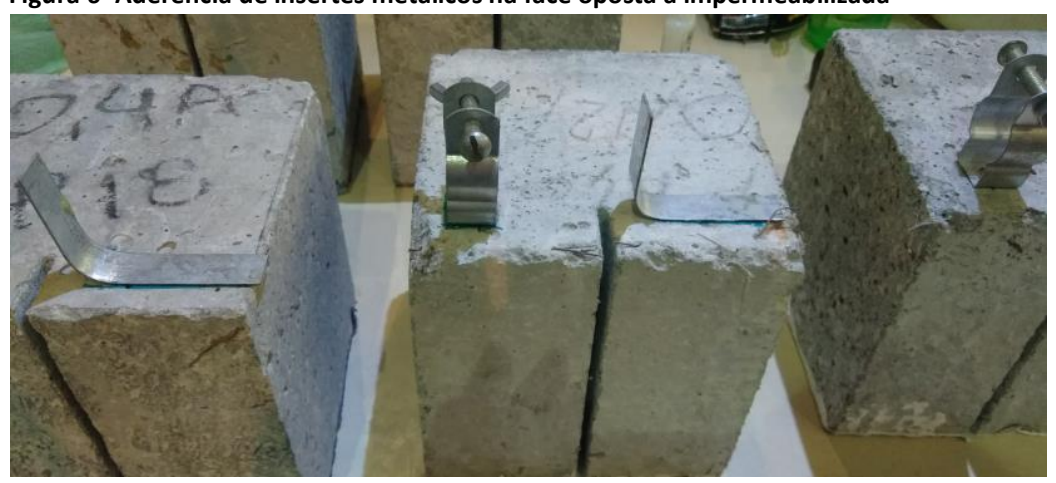

Fonte: os autores. 


\section{Procedimento de ensaio}

Para a realização do ensaio cada corpo de prova foi posicionado na máquina de ensaio universal (Shimadzu). A cunha metálica foi inserida na abertura do entalhe para que o esforço fosse conduzido continuamente. A aplicação da carga teve velocidade de deslocamento vertical constante de $0,5 \mathrm{~mm} \cdot \mathrm{min}^{-1}$.

O transdutor de deslocamento linear (LVDT) foi fixado nos insertes metálicos, localizados na face oposta à da membrana (Figura 7 a esquerda). Simultaneamente foi feita captação das imagens da superfície impermeabilizada por meio de vídeo (Figura 7 a direita). O tempo de início da filmagem foi sincronizado com o início do deslocamento vertical da máquina de ensaio. Desta forma, as leituras de deformação em ambas as superfícies poderiam ser correlacionadas dentro de um mesmo período de tempo. Para a filmagem foi utilizada uma câmera digital com lentes de distância focal $55 \mathrm{~mm}$, resolução de 2 megapixels e a captação de 2 imagens por segundo.

Figura 7- Face do substrato sem a membrana com LVDT (a esquerda) e face do substrato com a membrana filmada durante o ensaio (a direita)

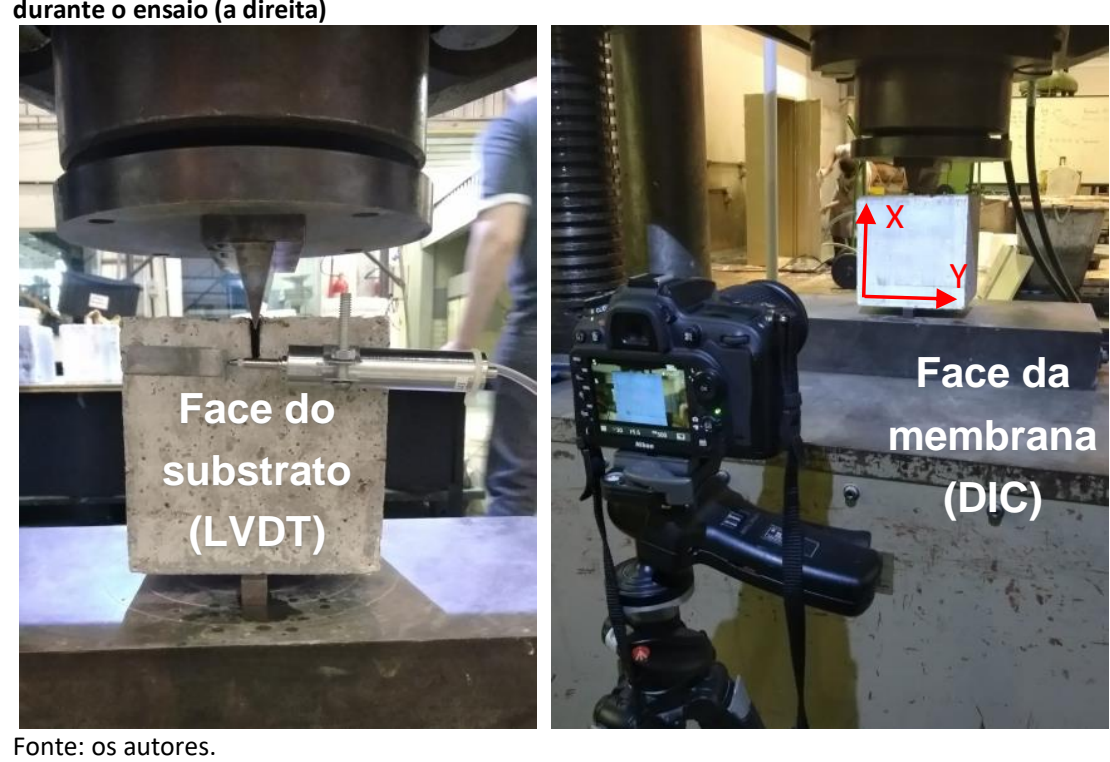

Após a finalização dos ensaios de transferência de fissura, os corpos de prova foram submetidos a ensaios de resistência de aderência à tração para avaliar a aderência das membranas. A metodologia utilizada teve como referência a norma NBR 12171 (ASSOCIAÇÃO BRASILEIRA DE NORMAS TÉCNICAS, 2019). O preparo das amostras para este ensaio teve como etapas: a marcação da área, o corte, a limpeza, a medição do diâmetro do corte e a colagem das pastilhas metálicas. Para cada corpo de prova foram realizados dois arrancamentos com uso de um dinamômetro de tração.

Processamento das imagens digitais $2 \mathrm{D}$ (DIC)

As imagens foram processadas com as ferramentas do software de correlação de imagem GOM. Na superfície impermeabilizada foram posicionados três extensômetros virtuais, como mostra a Figura 8. O extensômetro virtual (Extensômetro 1) que se encontrava posicionado mais próximo ao LVDT, em face oposta do substrato, foi adotado como referência para análise da deformação da membrana. Na etapa de pósprocessamento das imagens, o comportamento de deformação foi avaliado com intervalo de tempo $(\Delta t)$ de 1 segundo. 


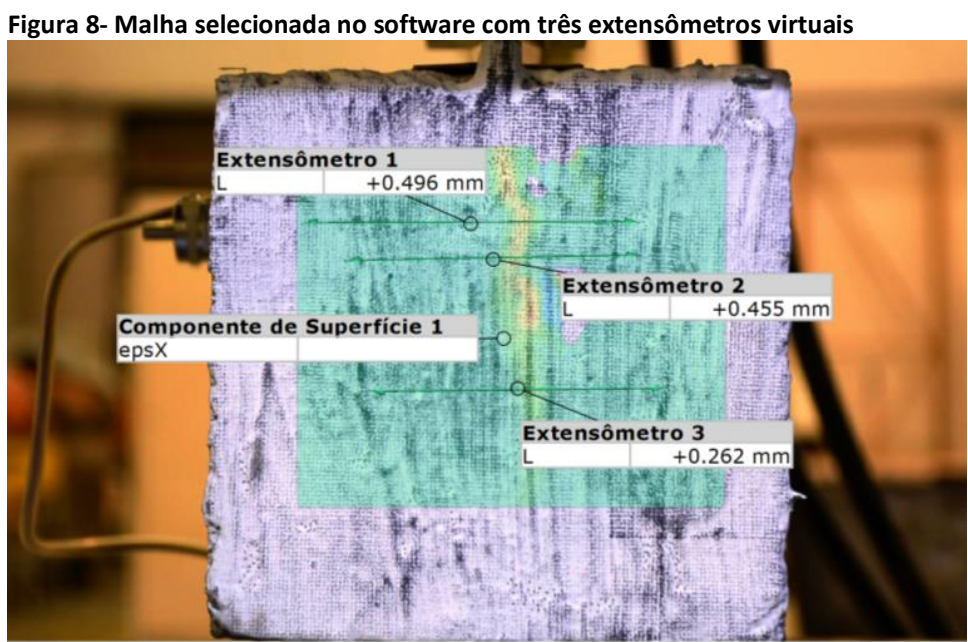

Fonte: os autores.

Para análise das deformações e aberturas de fissura foram utilizadas abordagens quantitativa e qualitativa. Para a avaliação quantitativa foram utilizadas as medidas de deformação no substrato de concreto (LVDT) e estas foram correlacionadas com a deformação na membrana impermeabilizante por meio do extensômetro virtual da análise das imagens digitais (DIC). A avaliação qualitativa utilizou as imagens pós processadas com o software GOM. Por meio da escala de cores do mapeamento de tensões e com os extensômetros posicionados na superfície foi possível detectar o momento de abertura de fissura na membrana.

\section{Resultados e discussões}

\section{Deformação no substrato e na membrana}

A Figura 9 apresenta, para a membrana de acrilatos puros (MAP), o deslocamento medido com LVDT na face do concreto conforme evoluiu o tempo de ensaio. A mesma figura a direita apresenta o comportamento avaliado simultaneamente na face impermeabilizada com uso da técnica DIC. Com a representação expandida dos gráficos, pode-se determinar o tempo e a deformação, em média, para ocorrer a fissuração do substrato de concreto (a esquerda) e da membrana (a direita). De forma análoga, o tempo e a deformação médios para a MAP foram determinados e os resultados são um pouco superiores que os obtidos no substrato. Contudo, cabe ressaltar que a membrana é um material polimérico com comportamento viscoelástico e essa deformação não indica necessariamente que a mesma fissurou.

Na Figura 10 estão apresentados os resultados para a membrana de copolímeros acrílicos sem cimento (MASC). À esquerda está apresentado o deslocamento medido com LVDT na face do concreto conforme evoluiu o tempo de ensaio. À direita está mostrado o comportamento avaliado simultaneamente na face impermeabilizada com uso da técnica DIC. Os gráficos expandidos permitem a determinação do tempo e da deformação, médios, para ocorrer a fissuração do substrato de concreto (a esquerda) e da membrana (a direita). Para a MASC, o tempo e a deformação médios também foram superiores aos obtidos no substrato, mas como já foi salientado essa deformação não indica necessariamente que a membrana fissurou. Nota-se também maior dispersão das curvas quando comparada com a MAP (Figura 9). 
SANTOS, J. A. B. dos; SANTOS, F. P.; MONTE, R.

Avaliação da transferência de fissuras em sistemas de impermeabilização aderidos

Figura 9- Evolução das deformaç̃̃es no tempo no substrato com uso do extensômetro real- LVDT (a esquerda) e na superfície impermeabilizada com uso do extensômetro virtual -DIC para a membrana de acrilatos puros (MAP), gráficos expandidos indicam o ponto de inflexão da curva
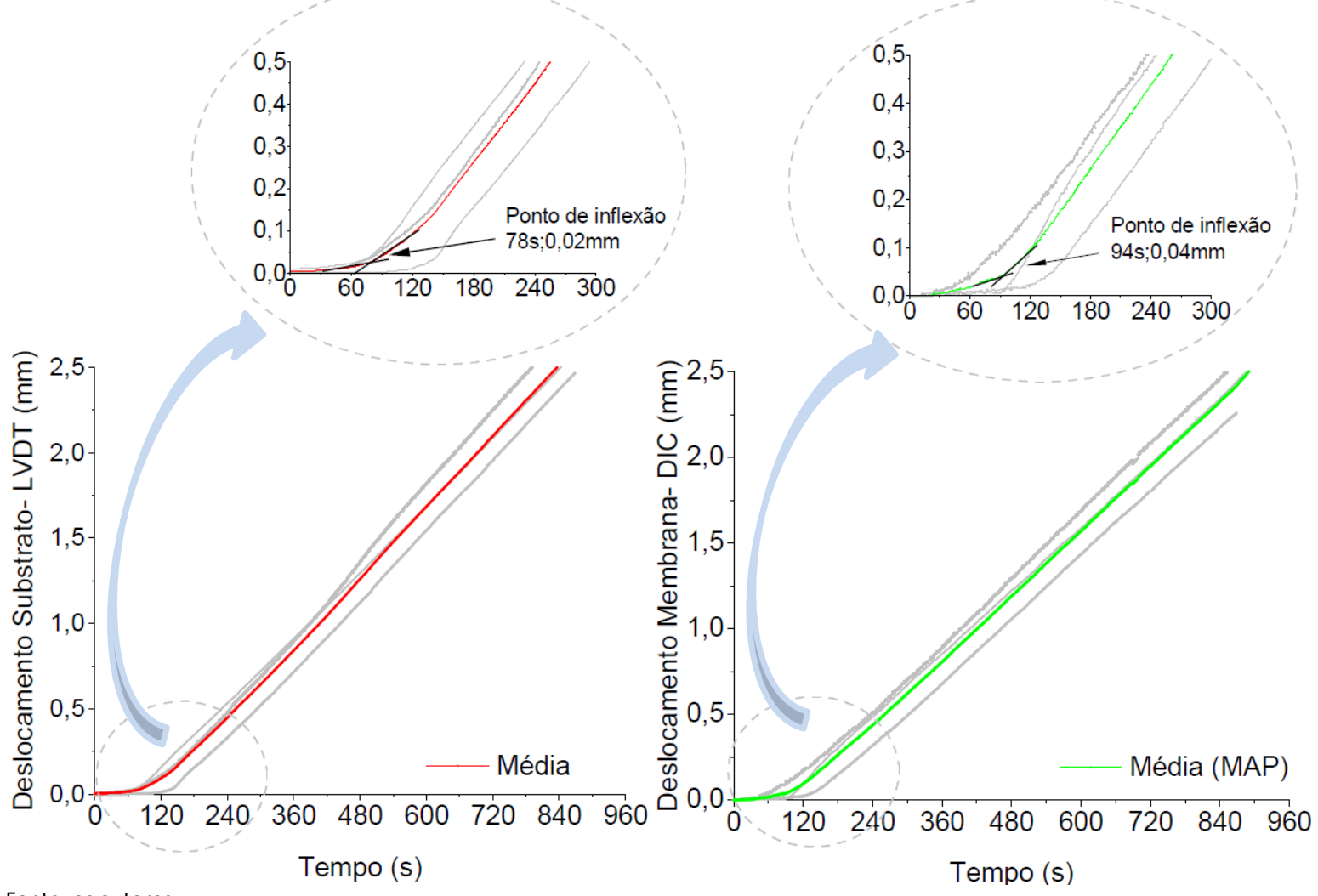

Fonte: os autores

Figura 10- Evolução das deformações no tempo no substrato com uso do extensômetro real - LVDT (a esquerda) e na superfície impermeabilizada com uso do extensômetro virtual - DIC (a direita) para a membrana copolímeros acrílicos sem cimento (MASC), gráficos expandidos indicam o ponto de inflexão da curva
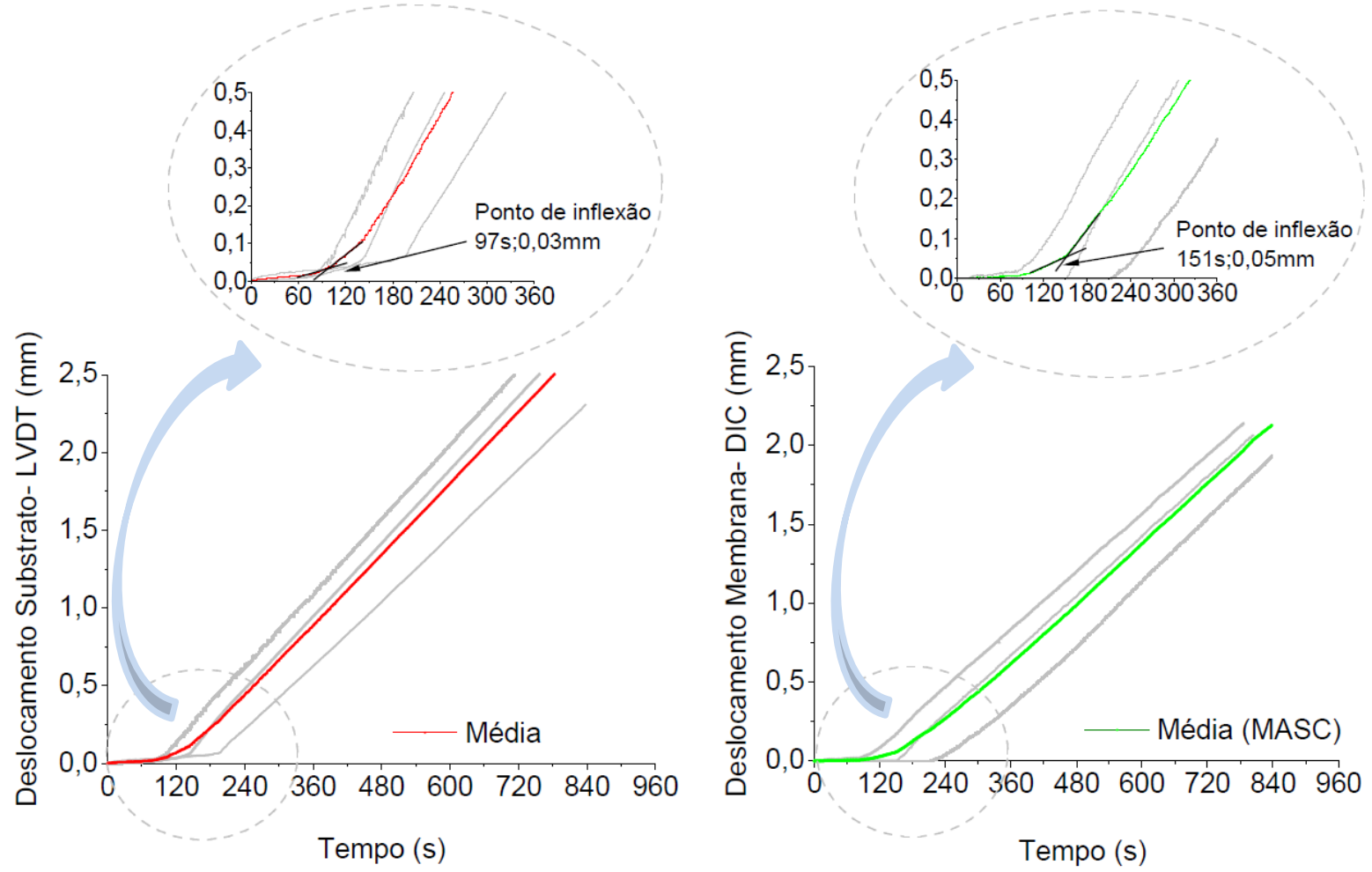

Tempo (s)

Fonte: os autores. 
SANTOS, J. A. B. dos; SANTOS, F. P.; MONTE, R.

Avaliação da transferência de fissuras em sistemas de impermeabilização aderidos

Um comparativo entre as curvas médias da deformação do substrato, medida com o LVDT, e da superfície impermeabilizada, medida com a técnica DIC, é apresentado na Figura 11.

Figura 11- Comparação entre curvas médias de deformação no substrato (Ext. Real) e na superfície impermeabilizada (ext. virtual), (a esquerda) membrana de acrilatos puros - MAP, (a direita) membrana de copolímeros acrílicos sem cimento - MASC

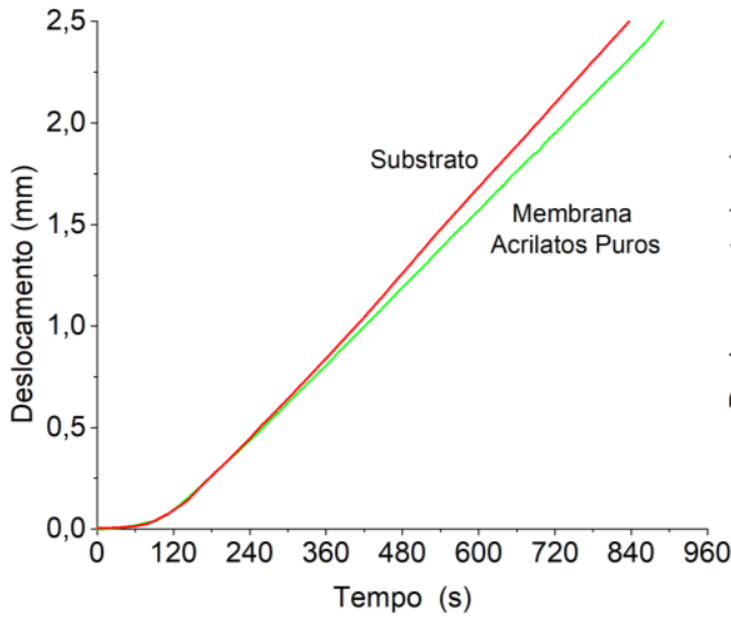

Ext. Real (LVDT)

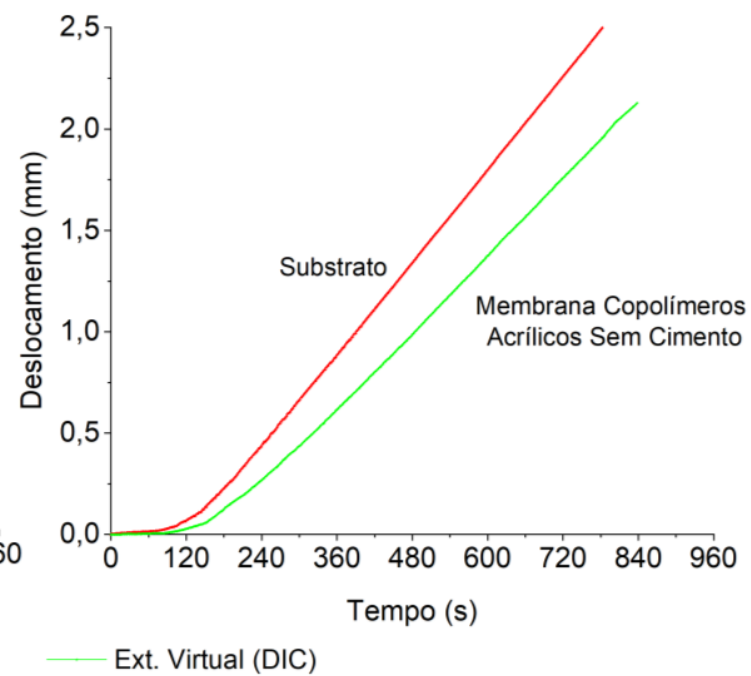

Fonte: os autores.

A deformação indicada pelo início das curvas do concreto e da MAP denotam comportamentos aproximados (Figura 10 a esquerda). Isto sugere que a superfície impermeabilizada absorveu os esforços quase simultaneamente com o concreto. Apesar disto, um afastamento das curvas é percebido a partir de aproximadamente 1 mm de deformação, o que indica uma certa capacidade de acomodação de deformações pela membrana. No caso da MASC o comportamento observado é diferente. Observase na Figura 10 a esquerda que a diferença na inclinação das curvas é mais acentuada e notada desde o início do deslocamento. Desses resultados já é possível depreender um comportamento superior da membrana MASC na ocorrência de fissuração do substrato.

Na Figura 12 foram correlacionados os deslocamentos médios obtidos no substrato e nas membranas. Com base na análise da Figura 12, é possível observar uma forte correlação linear $\left(R^{2}>0,99\right)$ entre os deslocamentos medidos no substrato (com LVDT) e aqueles medidos na membrana (com DIC).

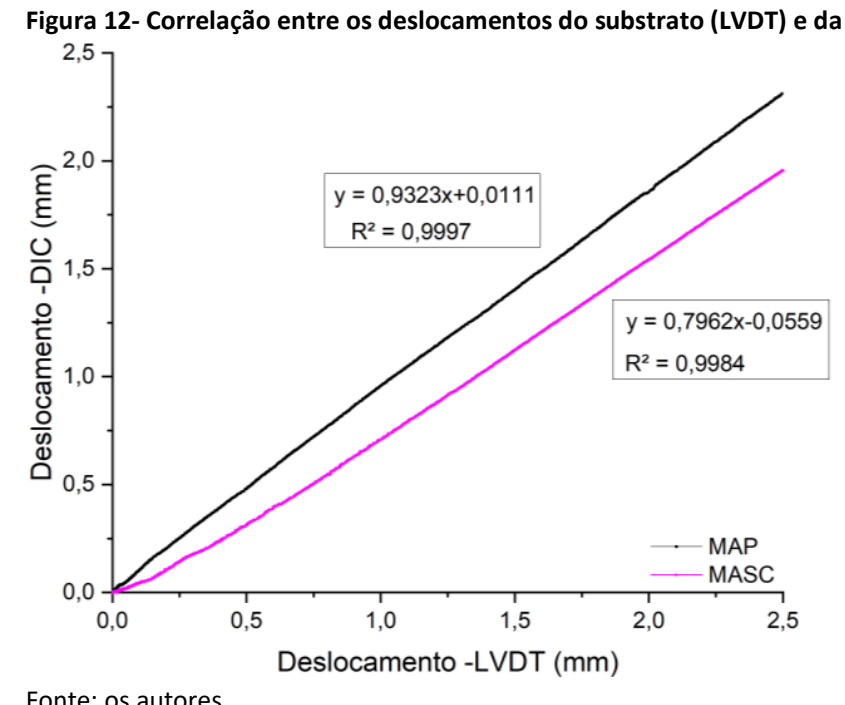

Fonte: os autores. 
Os coeficientes angulares indicam a relação entre os deslocamentos no substrato $(x)$ e na superfície das membranas (y), sendo o coeficiente da MASC igual a 0,7962 e da MAP igual a 0,9323. A significativa diferença entre esses coeficientes expressam o comportamento distinto das membranas frente a deformação do substrato.

\section{Identificação da abertura de fissura na membrana}

Conforme comentado as membranas são compostas por materiais poliméricos que apresentam comportamento viscoelástico e as deformações medidas não indicam necessariamente que ocorreu a fissuração. Por isso, uma avaliação qualitativa por meio da análise de imagens no software GOM foi conduzida para identificar o momento que as membranas fissuraram e os respectivos deslocamentos. A Figura 13 apresenta as análises de imagem do corpo de prova 2 da membrana de acrilatos puros para ilustrar as análises realizadas.

Figura 13- Abertura de fissura medidas pela técnica DIC na MAP (CP2), (a esquerda acima) abertura inicial percebida pela vista de medição da superfície do corpo de prova, (a direita acima) abertura detectada pelo mapeamento diferencial de tensões, (a esquerda abaixo) abertura final da membrana detectada pela vista de medição e (a direita abaixo) abertura final da membrana com vista do mapeamento de tensões na superfície
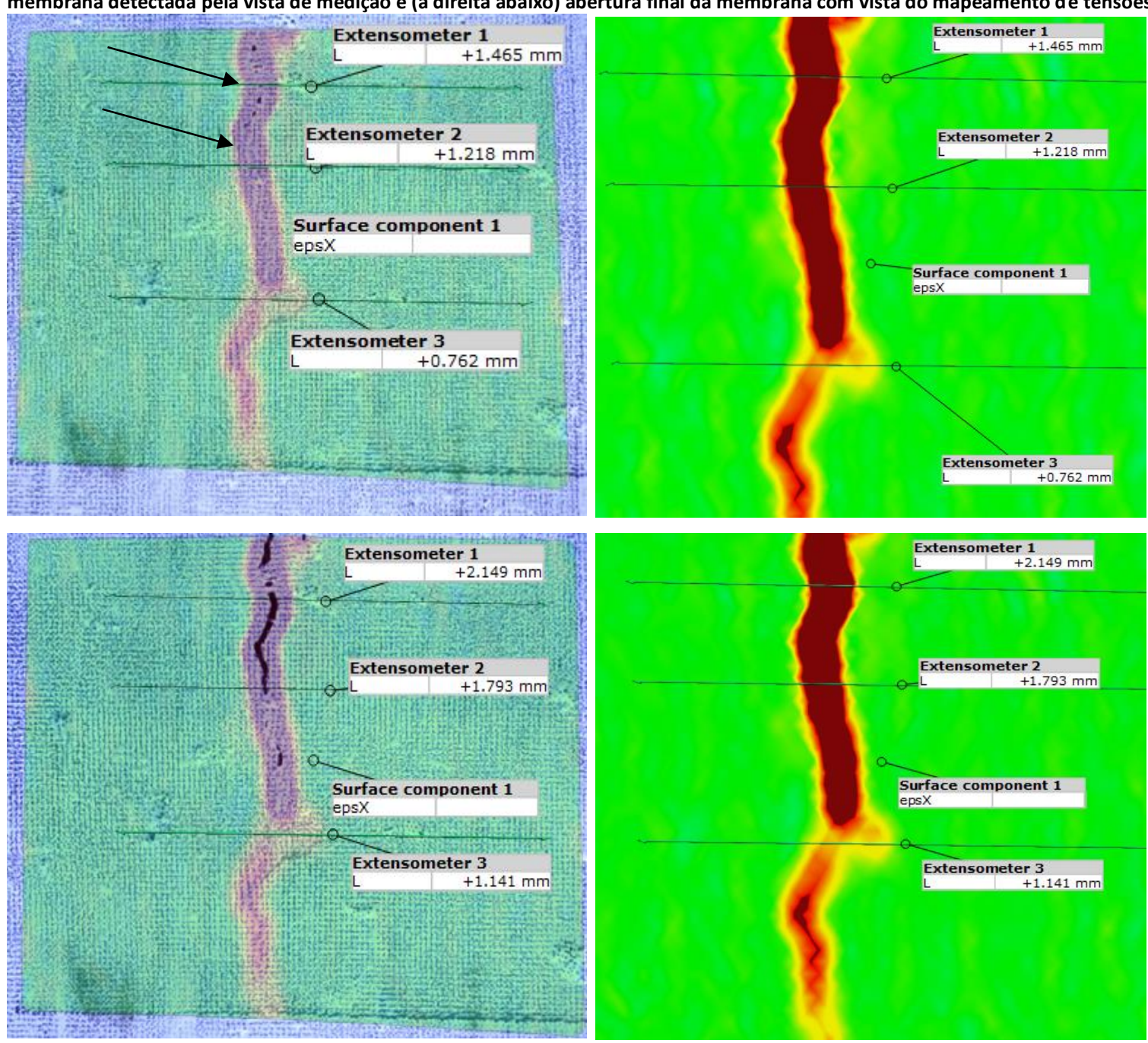

Fonte: os autores.

A Figura 13 (a esquerda acima) apresenta o surgimento de fissuras visíveis na membrana (setas pretas). A máxima ruptura observada na membrana é mostrada na Figura 13 (a esquerda abaixo). Já a Figura 13 (a esquerda acima e abaixo) indicam o mapeamento do campo de tensões no corpo de prova. Percebe-se que a área fissurada apresenta uma escala de cor vermelho escuro, indicando que as tensões de tração são maiores nestes 
pontos do que nas demais áreas da malha de estudo. Para verificação do momento inicial da ruptura da membrana foi necessário avaliar simultaneamente as vistas de medição do corpo de prova com o mapeamento de diferencial de tensões.

As medidas de deslocamento e do tempo em que se visualiza a fissura na superfície impermeabilizada são indicadas na Tabela 1. Estão apresentados também os respectivos deslocamentos no substrato e a diferença entre o deslocamento no substrato e na membrana $(\Delta \delta)$.

Tabela 1- Deslocamento $(\delta)$ e tempo $(\Delta T)$ relativos a fissura visível na membrana, correspondente deslocamento no substrato e a variação entre o deslocamento ocorrido na membrana e no substrato $(\Delta \delta)$

\begin{tabular}{ccccc}
\multicolumn{5}{c}{ MAP - Membrana de acrilatos puros } \\
\hline & $\begin{array}{c}\text { Deslocamento }(\delta) \\
\text { Substrato }(\mathrm{mm})\end{array}$ & $\begin{array}{c}\text { Deslocamento }(\delta) \\
\text { Membrana }(\mathrm{mm})\end{array}$ & $\begin{array}{c}\Delta \delta \\
(\mathrm{mm})\end{array}$ & $\begin{array}{c}\Delta \text { T fissura visual na } \\
\text { membrana }(\mathrm{s})\end{array}$ \\
\hline $\mathrm{CP} 1$ & 1,65 & 1,53 & 0,12 & 630 \\
\hline CP2 & 1,47 & 1,38 & 0,08 & 506 \\
\hline CP3 & 1,38 & 1,30 & 0,09 & 507 \\
\hline Média & 1,50 & 1,40 & 0,10 & 548 \\
\hline Desvio padrão & 0,14 & 0,12 & 0,02 & 71 \\
\hline Erro padrão & 0,08 & 0,07 & 0,01 & 41 \\
\hline
\end{tabular}

Fonte: os autores.

Os dados da Tabela 1 e Tabela 2 apontam deslocamentos superiores no substrato do que nas membranas no momento que se identifica a ruptura da membrana. Observa-se também que a MAP absorveu menos a fissura do substrato, apresentando uma diferença média de 0,10 $\mathrm{mm}$ frente aos 0,39 mm da MASC. Essa diferença pode ser explicada pelo maior alongamento da MASC em relação a MAP, conforme indicado no Quadro 2.

Tabela 2- Deslocamento $(\delta)$ e tempo $(\Delta T)$ correspondentes a fissura visual na membrana, correspondente abertura de fissura no substrato e variação $(\Delta \delta)$ entre o deslocamento ocorrido na membrana e no substrato

\begin{tabular}{ccccc}
\hline \multicolumn{5}{c}{ MASC - Membrana de copolímeros acrílicos sem cimento } \\
\hline & $\begin{array}{c}\text { Deslocamento }(\delta) \\
\text { Substrato }(\mathrm{mm})\end{array}$ & $\begin{array}{c}\text { Deslocamento }(\delta) \\
\text { Membrana }(\mathrm{mm})\end{array}$ & $\begin{array}{c}\Delta \delta \\
(\mathrm{mm})\end{array}$ & $\begin{array}{c}\Delta \text { T fissura visual na } \\
\text { membrana }(\mathrm{s})\end{array}$ \\
\hline $\mathrm{CP} 1$ & 1,72 & 1,38 & 0,34 & 673 \\
\hline $\mathrm{CP} 2$ & 1,93 & 1,47 & 0,47 & 571 \\
\hline CP3 & 1,31 & 0,96 & 0,35 & 454 \\
\hline Média & 1,66 & 1,27 & 0,39 & 566 \\
\hline Desvio padrão & 0,31 & 0,27 & 0,07 & 110 \\
\hline Erro padrão & 0,18 & 0,16 & 0,04 & 63 \\
\hline Fonte: os autores. & & & &
\end{tabular}

\section{Resistência de aderência}

Os resultados de resistência de aderência das membranas estão apresentados na Tabela 3. Atualmente, a norma NBR 13321 (ASSOCIAÇÃO BRASILEIRA DE NORMAS TÉCNICAS, 2008) que define os requisitos para as membranas de acrilatos puros não indica parâmetros de aceitabilidade da resistência de aderência. Porém, a norma de desempenho NBR 15575-5 (ASSOCIAÇÃO BRASILEIRA DE NORMAS TÉCNICAS, 2013) define que membranas totalmente aderidas ao substrato devem ter resistência de aderência à tração mínima de $0,2 \mathrm{MPa}$. No caso das membranas de copolímeros sem cimento, o requisito normativo é de resistência de aderência superior a 0,5 MPa. Observa-se que ambas as membranas apresentaram tensão média de aderência muito superiores aos parâmetros normativos.

As rupturas geradas na MAP foram do tipo coesiva no substrato para $50 \%$ das amostras. Para o restante, a ruptura foi do tipo adesiva, na interface entre o substrato e o primer. Isto justifica os valores elevados de tensão de ruptura, indicando grande força de aderência entre a camada mais interna da membrana e do substrato. 
Tabela 3- Resultados de resistência de aderência dos sistemas impermeabilizantes após ensaio de transferência de fissuras

\begin{tabular}{ccccc}
\hline Membrana & $\begin{array}{c}\text { Tensão } \\
\text { média } \\
(\mathrm{MPa})\end{array}$ & $\begin{array}{c}\text { Desvio Padrão } \\
(\mathrm{MPa})\end{array}$ & $\begin{array}{c}\text { Parâmetros } \\
\text { Comparativo } \\
(\mathrm{MPa})\end{array}$ & $\begin{array}{c}\text { Referência } \\
\text { normativa }\end{array}$ \\
\hline Acrilatos Puros & 1,9 & 0,4 & 0,2 & ABNT NBR 15575:5 \\
\hline Copolímeros acrílicos sem cimento & 1,6 & 0,3 & 0,5 & ABNT NBR 15885 \\
\hline Fonte: os autores. & & & &
\end{tabular}

A MASC teve formas de rupturas diversas, com predominância na interface entre o substrato e o primer, em $60 \%$ das amostras. Rupturas adesivas entre a camada do primer e impermeabilizante também foram notadas para $20 \%$ das amostras.

Como constatado em estudos anteriores quando a membrana se mantém com forte aderência no substrato durante a transferência de esforços há tendência de rupturas na camada impermeável com menor alongamento (DELUCCHI et al., 2002; WALDVOGEL et al., 2020b). Isto implica que à medida que ocorre aumento da aderência da membrana no substrato pode haver menor resistência a fissuração da membrana.

\section{Conclusão}

O trabalho apresentou uma metodologia experimental com aplicação de um ensaio mecânico de tração indireta, inspirado no ensaio WST (Wedge Splitting Test), para avaliação da transferência de fissuras de substratos de concreto para membranas impermeabilizantes aderidas. Ainda, a análise por correlação de imagem (DIC) foi apresentada como alternativa para o acompanhamento das fissuras do substrato de concreto e das deformações ocorridas nas membranas. Com os resultados obtidos as seguintes conclusões podem ser destacadas.

A metodologia apresentada foi capaz de diferenciar o comportamento das duas membranas avaliadas quanto a capacidade de resistir à transferência de fissura originada no substrato. A técnica DIC se mostrou adequada para o monitoramento das fissuras. Isto possibilitou a identificação do momento da transferência da fissura do substrato para a membrana e a quantificação da deformação que ocorre na membrana.

A membrana de acrilatos puros tem menor tendência a absorver esforços provenientes do substrato do que a membrana de copolímeros acrílicos sem cimento. A diferença no alongamento dos materiais, conforme indicado pelo fabricante, é compatível com os resultados obtidos, ou seja, o material que tem maior alongamento é capaz de absorver mais a fissuração. A aderência das membranas ao substrato foi elevada e muito superior aos requisitos normativos. Isto tem relação com a transferência de fissuras do substrato para a camada aderida, o que pode ter levado a dificuldade das membranas em absorver os esforços do substrato, fissurando com maior facilidade.

\section{Nota}

Este artigo é uma versão estendida do artigo "PROPOSTA DE METODOLOGIA PARA AVALIAÇÃO DA TRANSFERÊNCIA DE FISSURAS ENTRE O SUBSTRATO E O SISTEMA DE IMPERMEABILIZAÇÃO ADERIDO” (BRAUN; SANTOS; MONTE, 2019) apresentado pelos autores no $2^{\circ}$ WORKSHOP DE TECNOLOGIA DE PROCESSOS E SISTEMAS CONSTRUTIVOS.

\section{Referências}

AMERICAN SOCIETY FOR TESTING AND MATERIALS. C1305/C1305M: Standard Test Method for Crack Bridging Ability of Liquid-Applied Waterproofing MembraneWest Conshohocken, United States, 2016.

ASSOCIAÇÃO BRASILEIRA DE NORMAS TÉCNICAS. NBR 13321: Membrana acrílica para impermeabilização. Rio de 
SANTOS, J. A. B. dos; SANTOS, F. P.; MONTE, R.

Avaliação da transferência de fissuras em sistemas de impermeabilização aderidos

Janeiro, 2008.

ASSOCIAÇÃO BRASILEIRA DE NORMAS TÉCNICAS. NBR 15885: Membrana de polímero acrílico com ou sem cimento, para impermeabilização. Rio de Janeiro, 2010.

ASSOCIAÇÃO BRASILEIRA DE NORMAS TÉCNICAS. NBR 15575: Edificações habitacionais — Desempenho Parte 5: Requisitos para os sistemas de coberturas. Rio de Janeiro, 2013.

ASSOCIAÇÃO BRASILEIRA DE NORMAS TÉCNICAS. NBR 12171: Aderência aplicável em sistema de impermeabilização composto por cimento impermeabilizante e polímeros. Rio de Janeiro, 2019.

BRAUN, J.; SANTOS, F.; MONTE, R.. Proposta de metodologia para avaliação da transferência de fissuras entre o substrato e o sistema de impermeabilização aderido. In: WORKSHOP DE TECNOLOGIA DE PROCESSOS E SISTEMAS CONSTRUTIVOS, 2., 2019, Brasil. Anais [...] São Paulo: IPT, 2019. Disponível em:

<https://antaceventos.net.br/index.php/tecsic/tecsic2019/paper/view/322>. Data de acesso: 13 Jan. 2021.

BRÜHWILER, E.; WITTMANN, F. H. The wedge splitting test, a new method of performing stable fracture mechanics tests. Engineering Fracture Mechanics, Great Britain, v. 35, p. 117-125, 1990. DOI: https://doi.org/10.1016/00137944(90)90189-N.

CALLISTER, Willian. Fundamentos da Ciência e engenharia de materiais: uma abordagem integrada. 4. ed. Rio de Janeiro: LTC, 2018.

CHIEN, Chi Hui; SU, Ting Hsuan; HUANG, Chao Jian; CHAO, Yuh Jin; YEH, Wei Li; LAM, Poh Sang. Application of digital image correlation (DIC) to sloshing liquids. Optics and Lasers in Engineering, v. 115, n. August 2018, p. 42-52, 2019. DOI: https://doi.org/10.1016/j.optlaseng.2018.11.016.

DEL REY CASTILLO, Enrique; ALLEN, Tom; HENRY, Richard; GRIFFITH, Michael; INGHAM, Jason. Digital image correlation (DIC) for measurement of strains and displacements in coarse, low volume-fraction FRP composites used in civil infrastructure. Composite Structures, v. 212, n. January, p. 43-57, 2019. DOI: https://doi.org/10.1016/j.compstruct.2019.01.024.

DELUCCHI, M.; BARBUCCI, A.; CERISOLA, G. Crack-bridging ability of organic coatings for concrete: influence of the method of concrete cracking, thickness and nature of the coating. Progress in Organic Coatings, v. 49, n. 4, p. 336341, 2004. DOI: https://doi.org/10.1016/j.porgcoat.2003.09.016.

DELUCCHI, M.; BARBUCCI, A.; TEMTCHENKO, T.; POGGIO, T.; CERISOLA, G. Study of the crack-bridging ability of organic coatings for concrete: analysis of the mechanical behaviour of unsupported and supported films. Progress in Organic Coatings, v. 44, n. 4, p. 261-269, 2002. DOI: https://doi.org/10.1016/S0300-9440(02)00054-1.

DELUCCHI, M.; CERISOLA, G. Influence of thickness on mechanical properties and crack-bridging ability of coatings for concrete. Progress in Organic Coatings, v. 54, n. 4, p. 305-309, 2005. DOI:

https://doi.org/10.1016/j.porgcoat.2005.07.005.

DELUCCHI, M.; CERISOLA, G. Influence of temperature on crack-bridging ability of coatings for concrete. Progress in Organic Coatings, v. 75, n. 3, p. 253-258, 2012. DOI: https://doi.org/10.1016/j.porgcoat.2012.05.006

DIAMANTI, M. V.; BRENNA, A.; BOLZONI, F.; BERRA, M.; PASTORE, T.; ORMELLESE, M. Effect of polymer modified cementitious coatings on water and chloride permeability in concrete. Construction and Building Materials, v. 49, p. 720-728, 2013. DOI: https://doi.org/10.1016/j.conbuildmat.2013.08.050.

EUROPEAN ORGANISATION FOR TECHNICAL APPROVALS. Technical Report 013: Determination of crack-bridging capability.2004. Disponível em: https://www.eota.eu/en-GB/content/technical-reports/28/.

EUROPEAN ORGANISATION FOR TECHNICAL APPROVALS. Technical Report 033:Test method for discontinuously laid bituminous roof covering products - Determination of watertightness. 2009. 
EUROPEAN ORGANISATION FOR TECHNICAL APPROVALS. European Technical Approval Guidelines 033: Liquid Applied Bridge Deck Waterproofing Kits. Brussels, 2010. Disponível em: https://www.eota.eu/enGB/content/etags/26/.

EUROPEAN STANDARD. 1062-7: Paints and varnishes Coating materials and coating systems for exterior masonry and concrete Part 7: Determination of crack bridging properties.Brussels, 2004.

EUROPEAN STANDARD. 14224: Flexible sheets for waterproofing - Waterproofing of concrete bridge decks and other concrete surfaces trafficable by vehicles - Determination of crack bridging abilityBrussels, 2010.

EUROPEAN STANDARD. 14891: Liquid applied water impermeable products for use beneath ceramic tiling bonded with adhesives - Requirements, test methods, assessment and verification of constancy of performance, classification and marking.Brussels, 2017.

GLASSER, Fredrik P.; MARCHAND, Jacques; SAMSON, Eric. Durability of concrete - Degradation phenomena involving detrimental chemical reactions. Cement and Concrete Research, v. 38, n. 2, p. 226-246, 2008. DOI: https://doi.org/10.1016/j.cemconres.2007.09.015.

GRIBNIAK, Viktor; RIMKUS, Arvydas; PÉREZ CALDENTEY, Alejandro; SOKOLOV, Aleksandr. Cracking of concrete prisms reinforced with multiple bars in tension-the cover effect. Engineering Structures, v. 220, p. 110979, 2020. DOI: https://doi.org/10.1016/j.engstruct.2020.110979.

HOLTER, Karl Gunnar. Performance of EVA-Based membranes for SCL in hard rock. Rock Mechanics and Rock Engineering, v.49, n.4, p.1329-1358, 2016. DOI: https://doi.org/10.1007/s00603-015-0844-5.

INTERNATIONAL DIGITAL IMAGE CORRELATION SOCIETY. A Good Practices Guide for Digital Image Correlation. 2018. DOI: https://doi.org/10.32720/idics/gpg.ed1.

ISSA, Camille A.; DEBS, Pauls. Experimental study of epoxy repairing of cracks in concrete. Construction and Building Materials, v. 21, n. 1, p. 157-163, 2007. DOI: https://doi.org/10.1016/j.conbuildmat.2005.06.030.

JAEGERMANN, C.; PUTERMAN, M. The evaluation of the crack-bridging ability of exposed roof coatings. Materials and Structures, v. 20, n. 6, p. 403-407, 1987. DOI: https://doi.org/10.1007/BF02472490.

KONG, Lijuan; FANG, Jun; ZHOU, Xiangming; HAN, Mengdi; LU, Haoran. Assessment of coatings for protection of cement paste against microbial induced deterioration through image analysis. Construction and Building Materials, v. 191, p. 342-353, 2018. DOI: https://doi.org/10.1016/j.conbuildmat.2018.10.041.

KUBAL, Michael T. Construction Waterproofing Handbook, p.33, 2. ed. United States. ISBN 0071489738.

LEPAGE, W. S.; SHAW, J. A.; DALY, S. H. Optimum Paint Sequence for Speckle Patterns in Digital Image Correlation. Experimental Techniques, v. 41, n. 5, p. 557-563, 2017. DOI: https://doi.org/10.1007/s40799-017-0192-3.

LIU, Wei He; ZHANG, Lu Wen; LIEW, K. M. Modeling of crack bridging and failure in heterogeneous composite materials: A damage-plastic multiphase model. Journal of the Mechanics and Physics of Solids, v. 143, p. 104072, 2020. DOI: https://doi.org/10.1016/j.jmps.2020.104072.

MENGEL, Lena; KRAUSS, Hans Werner; LOWKE, Dirk. Water transport through cracks in plain and reinforced concrete - Influencing factors and open questions. Construction and Building Materials, 2020. DOI: https://doi.org/10.1016/j.conbuildmat.2020.118990.

RIBEIRO, S.; EXPOSITO, C. C. D.; RODRIGUES, J.; CARLOS, S. Projeto, adaptação, instalação e testes preliminares para um sistema de medida de energia de fratura de materiais cerâmicos pelo método da cunha. Cerâmica, v. 54, p. 418-426, 2008.DOI: https://doi.org/10.1590/S0366-69132008000400006.

SEGURA-CASTILLO, Luis; MONTE, Renata; DE FIGUEIREDO, Antonio D. Characterisation of the tensile constitutive behaviour of fibre-reinforced concrete: A new configuration for the Wedge Splitting Test. Construction and 
SANTOS, J. A. B. dos; SANTOS, F. P.; MONTE, R.

Avaliação da transferência de fissuras em sistemas de impermeabilização aderidos

Building Materials, v. 192, p. 731-741, 2018. DOI: https://doi.org/10.1016/j.conbuildmat.2018.10.101.

SRIRAVINDRARAJAH, Rasiah; TRAN, Elizebeth. Waterproofing practices in Australia for building construction. MATEC Web of Conferences, v.195. The $4^{\text {th }}$ International Conference on Rehabilitation and Maintenance in Civil Engineering, 2018. DOI: http://dx.doi.org/10.1051/matecconf/201819501002.

SUTTON, M. A.; YAN, J. H.; TIWARI, V.; SCHREIER, H. W.; ORTEU, J. J. The effect of out-of-plane motion on 2D and 3D digital image correlation measurements. Optics and Lasers in Engineering, v. 46, n. 10, p. 746-757, 2008. DOI: https://doi.org/10.1016/j.optlaseng.2008.05.005.

VAN LOOCK, Frederik; FLECK, Norman A. Deformation and failure maps for PMMA in uniaxial tension. Polymer, v. 148, p. 259-268, 2018. DOI: https://doi.org/10.1016/j.polymer.2018.06.027.

WALDVOGEL, Marius; ZURBRIGGEN, Roger; BERGER, Alfons; HERWEGH, Marco. The microstructural evolution of cementitious, flexible waterproofing membranes during deformation with special focus on the role of crazing. Cement and Concrete Composites, v. 107, p. 103494, 2020a. DOI: https://doi.org/10.1016/j.cemconcomp.2019.103494.

WALDVOGEL, Marius; ZURBRIGGEN, Roger; BERGER, Alfons; HERWEGH, Marco. Influences of temperature and opening rate of substrate cracks on the mechanical behaviour, crack-bridging ability and deformation mechanisms of one-component, cementitious, flexible waterproofing membranes. Cement and Concrete Research, v. 136, p. 106140, 2020b. DOI: https://doi.org/10.1016/j.cemconres.2020.106140.

ZHAO, Hong; LI, Wei; ZHANG, Yong Ming. Study on Crack Bridging Ability of Polymer-Modified Cement Based Compounds for Waterproofing Material. Advanced Materials Research, v. 1129, p. 217-221, 2015. DOI: https://doi.org/10.4028/www.scientific.net/AMR.1129.217.

\section{Julie Anne Braun dos Santos}

Engenheira Civil. Especialista em Construção Civil: Residenciais, Industriais e Especiais, pela faculdade UNYLEYA. Mestranda na Universidade de São Paulo, Escola Politécnica, Departamento de Engenharia de Construção Civil, Programa de Mestrado Profissional em Inovação na Construção Civil. Endereço Postal: Universidade de São Paulo, Av. Professor Almeida Prado, Trav.2, n 83, CEP 05508-900.

\section{${ }^{2}$ Felipe Pereira Santos}

Engenheiro Civil. Mestrando na Universidade de São Paulo, Escola Politécnica, Departamento de Engenharia de Construção Civil, Programa de Pós-Graduação em Engenharia Civil. Endereço Postal: Universidade de São Paulo, Av. Professor Almeida Prado, Trav.2, n 83, CEP 05508-900.

\section{${ }^{3}$ Renata Monte}

Engenheira Civil. Doutora em Ciências pela Universidade de São Paulo. Professora Orientadora do Programa de Mestrado Profissional em Inovação na Construção Civil. Especialista de laboratório da Universidade de São Paulo. Endereço Postal: Universidade de São Paulo, Av. Professor Almeida Prado, Trav.2, n 83, CEP 05508-900. 